\title{
Genetic diversity and population structure of indigenous chicken of Bangladesh using microsatellite markers
}

\author{
Muhammad Abdur Rashid ${ }^{1,2}$, Prabuddha Manjula, Shakila Faruque ${ }^{2}$, A. K. Fazlul Haque Bhuiyan', \\ Dongwon $\mathrm{Seo}^{3}$, Jahangir Alam ${ }^{4}$, Jun Heon Lee ${ }^{3, *}$, and Mohammad Shamsul Alam Bhuiyan ${ }^{1, *}$
}

\author{
* Corresponding Authors: \\ Jun Heon Lee \\ Tel: +82-010-5172 0816, Fax: +82-42-825-9754, \\ E-mail: junheon@cnu.ac.kr \\ Mohammad Shamsul Alam Bhuiyan \\ Tel: +88-017-4574-8849, Fax: +88-091-61510, \\ E-mail: msabhuiyan@gmail.com \\ ${ }^{1}$ Department of Animal Breeding and \\ Genetics, Bangladesh Agricultural University, \\ Mymensingh-2202, Bangladesh \\ 2 Poultry Production Research Division, Bangladesh \\ Livestock Research Institute, Dhaka-1341, \\ Bangladesh \\ ${ }^{3}$ Division of Animal and Dairy Science, Chungnam \\ National University, Daejeon 34134, Korea \\ ${ }^{4}$ Animal Biotechnology Division, National Institute of \\ Biotechnology, Dhaka-1349, Bangladesh \\ ORCID \\ Muhammad Abdur Rashid \\ https://orcid.org/0000-0001-7444-9730 \\ Prabuddha Manjula \\ https://orcid.org/0000-0001-8074-8323 \\ Shakila Faruque \\ https://orcid.org/0000-0001-8635-0869 \\ A. K. Fazlul Haque Bhuiyan \\ https://orcid.org/0000-0002-1917-6386 \\ Dongwon Seo \\ https://orcid.org/0000-0003-0548-7068 \\ Jahangir Alam \\ https://orcid.org/0000-0001-5439-1412 \\ Jun Heon Lee \\ https://orcid.org/0000-0003-3996-9209 \\ Mohammad Shamsul Alam Bhuiyan
}

https://orcid.org/0000-0003-1525-2182

Submitted Mar 27, 2020; Revised Jun 5, 2020;

Accepted Jul 13, 2020
Objective: The objectives of this study were to investigate the genetic diversity, population structure and relatedness among the five chicken populations of Bangladesh using microsatellite markers.

Methods: A total of 161 individuals representing 5 chicken populations (non-descript Deshi $[\mathrm{ND}]$, naked neck [NN], hilly [HI], Aseel [AS], and red jungle fowl [JF]) were included in this study to investigate genetic diversity measures, population structure, genetic distance and phylogenetic relationships. Genotyping was performed using 16 selected polymorphic microsatellite markers distributed across 10 chromosomes.

Results: The average observed and expected heterozygosity, mean number of alleles and polymorphic information content were found to be $0.67 \pm 0.01,0.70 \pm 0.01,10.7$ and 0.748 , respectively in the studied populations. The estimated overall fixation index across the loci $(\mathrm{F})$, heterozygote deficiency within $\left(\mathrm{F}_{\mathrm{IS}}\right)$ and among $\left(\mathrm{F}_{\mathrm{IT}}\right)$ chicken populations were $0.04 \pm 0.02$, 0.05 and 0.16 , respectively. Analysis of molecular variance analysis revealed $88.07 \%$ of the total genetic diversity was accounted for within population variation and the rest $11.93 \%$ was incurred with population differentiation $\left(\mathrm{F}_{\mathrm{ST}}\right)$. The highest pairwise genetic distance (0.154) was found between ND and AS while the lowest distance was between JF and AS (0.084). Structure analysis depicted that the studied samples can be categorized into four distinct types or varieties $(\Delta \mathrm{K}=3.74)$ such as $\mathrm{ND}, \mathrm{NN}$, and $\mathrm{HI}$ where AS and JF clustered together as an admixed population. The Neighbor-Joining phylogenetic tree and discriminant analysis of principal component also showed close relatedness among three chicken varieties namely AS, HI, and JF.

Conclusion: The results reflected that indigenous chicken of Bangladesh still possess rich genetic diversity but weak differentiation among the studied populations. This finding provides some important insight on genetic diversity measures that could support the designing and implementing of future breeding plans for indigenous chickens of Bangladesh.

Keywords: Indigenous Chicken; Genetic Diversity; Microsatellite Marker; Bangladesh

\section{INTRODUCTION}

Poultry takes a vital place in global food chain. In fact, poultry is an integral part of rural households in the least developed countries around the world. There are about 255.31 million chickens in commercial and subsistence production systems in Bangladesh [1]. Among poultry, the chicken population is almost $90 \%$, followed by ducks ( $8 \%$ ) and rest $2 \%$ occupied by quail, pigeon, geese, and others [2]. The national share of commercial strains of chicken and indigenous family poultry in terms of egg production is almost equal (50:50) and that of meat production is $60: 40$ [3].About $89 \%$ of rural households keep indigenous chicken with an average flock size of 5.33 per holding under a backyard scavenging system that reflects the significance of indigenous chicken in Bangladesh perspective [4,5]. All elites, 
most city dwellers and some village level customers appreciate egg and meat produced from indigenous (deshi) chicken reared in scavenging system because their products are produced organically.

Indigenous chickens are lower in productivity but are well adapted to adverse tropical climate and fluctuating nutritional conditions compared to exotic chicken. However, the preferences for free-range indigenous chicken might be attributed to typical pigmentation, taste, leanness, firmness, high protein content and suitability for special dishes $[3,6]$. The identification, collection, evaluation, and conservation of different genotypes are an insurance against future need for breeding [7]. In this regard, unselected random mated indigenous chickens are considered as a huge treasure of many known and unknown genotypes, which could be beneficial to provide valuable additional attributes to the future poultry production. According to Bhuiyan et al [5], non-descript Deshi (ND), naked neck (NN), hilly (HI), and Aseel (AS) chickens are noteworthy among the indigenous chicken genetic resources of Bangladesh. It is notable to mention that Bangladesh Livestock Research Institute (BLRI) has undertaken a planned and systematic native chicken breeding program since 2000 and has improved the productivity of three different native chicken varieties (ND, HI, and NN) [8]. The productivity of the said genotypes has increased remarkably over the generations through selective breeding on-station in comparison to existing indigenous chicken varieties. Based on the mitochondrial DNA sequence polymorphisms, Bhuiyan et al [5] suggested that Bangladeshi indigenous chickens still possessed abundant genetic diversity and have originated from multiple maternal lineages. Apart from this, genetic characterization of these varieties has not yet been sufficiently explored which is a prerequisite to knowing within and between population differentiation in order to establish them as breeds or varieties.

Microsatellites are widely used DNA markers for exploring genetic variation and phylogeny among populations of same species $[9,10]$. The usefulness of microsatellite (MS) markers in estimating genetic relatedness and diversity in chickens have been demonstrated in several indigenous breeds, inbred strains and in commercial chicken lines [11-14]. Although molecular genetic characterization of indigenous chicken of Bangladesh has been performed based on mitochondrial DNA, characterization using nuclear genomic DNA is absent until to date. Hence, it would be worthwhile to know the genetic diversity and population structures of available chicken varieties of Bangladesh for development of a proper conservation and breeding strategy. Here, we investigate three indigenous chicken varieties that have been maintained at BLRI along with red jungle fowl (JF) and AS chickens for assessing their genetic diversity, genetic distance and population structure using 16 highly polymorphic MS markers.

\section{MATERIALS AND METHODS}

\section{Sample collection and DNA extraction}

Institutional Animal Care and Use Committee (IACUC) reviewed the total experimental procedure and prior approval was obtained from IACUC for this experiment (Approval number: BLRI-PCUC-003). In total, 161 unrelated blood samples were collected from 5 different chicken populations of Bangladesh: ND ( $\mathrm{n}=41), \mathrm{NN}(\mathrm{n}=44), \mathrm{HI}(\mathrm{n}=39)$, AS ( $\mathrm{n}$ $=18)$, and JF $(\mathrm{n}=19)$. The Native Chicken Conservation and Improvement Project of BLRI maintains ND, NN, and HI flocks and these birds were used for sampling. Besides, blood samples of AS chicken were collected from Bangladesh Agricultural University (BAU) research flock as well as from the farmers of Brahmanbaria district. JF sampling was performed from their breeding habitats, Chittagong Hill Tract regions $\left(22.20^{\circ} \mathrm{N}\right.$ and $\left.92.35^{\circ} \mathrm{E}\right)$. According to Bhuiyan et al [5], two different sub-species of JF are available in Bangladesh; Gallus gallus gallus and Gallus gallus spadiceus. However, blood samples were not categorized as per sub-species level for this study. All possible precautions were taken during sampling from unrelated individuals to prevent cross contamination. The blood samples were collected from wing veins by 3.0 $\mathrm{mL}$ disposable syringe and were stored either in vacutainer containing ethylene di-amine tetra acetic acid or in Flinders Technology Associates (FTA) classic card. The vacutainers and classic cards were then labeled with the name of chicken variety, age and sex of the birds and date of collection. The genomic DNA from whole blood samples and FTA card was extracted using both DNA isolation kit (Jena bioscience, Germany and GeNet Bio, Daejeon, Korea) and phenol-chloroform method.

\section{Polymerase chain reaction amplification and genotyping}

Selection of primers and polymerase chain reaction amplification: Sixteen (16) highly polymorphic MS markers were selected from the list of markers previously reported in Cho et al [15], which were selected from the ark database (http:// www.thearkdb.org/using-arkdb/). Forward primers were labelled and modified with four types of fluorescence dye. The detailed information for primers used in this study is mentioned in Cho et al [15]. Multiplex polymerase chain reaction (PCR) for total of 161 DNA samples was performed in a $20 \mu \mathrm{L}$ reaction volume. The PCR master mixture was consisting of $2.0 \mu \mathrm{L}$ of $25 \mathrm{ng} / \mu \mathrm{L}$ gDNA, $10 \mu \mathrm{L}$ of HS Prime multiplex PCR buffer (GeNet Bio, Korea) and $0.5 \mu \mathrm{L}$ of 5 pmol forward and reverse primer and appropriate volume of triple distilled water to adjust the total volume. PCR was performed in an initial denaturation at $94^{\circ} \mathrm{C}$ for $10 \mathrm{~min}$ followed by 35 cycles of denaturation at $94^{\circ} \mathrm{C}$ for $30 \mathrm{~s}$, annealing temperature at $60^{\circ} \mathrm{C}$ for $30 \mathrm{~s}$, extension temperature 
at $72^{\circ} \mathrm{C}$ for $30 \mathrm{~s}$ and final extension at $72^{\circ} \mathrm{C}$ for 20 min using the C1000 Thermal Cycler (Bio-Rad, Irvine, CA, USA). PCR amplifications products were confirmed by $2.0 \%$ agarose gel electrophoresis.

Microsatellite genotyping: Fragment analysis was performed by capillary electrophoresis array using the Genetic analyser 3,130 xl (Applied Biosystems, Foster City, CA, USA). The genotyping reaction was performed in a $10 \mu \mathrm{L}$ total volume including $1.0 \mu \mathrm{L}$ of diluted PCR product, $10 \mu \mathrm{L}$ of $\mathrm{Hi}-\mathrm{Di}$ formamide (Applied Biosystems, USA) and $0.1 \mu \mathrm{L}$ of the GeneScan-500LIZ size standard (Applied Biosystems, USA). The genotyping results were obtained using GeneMapper software ver. 3.7 (Applied Biosystems, USA).

\section{Data analysis}

At first raw data were checked using MS tool kit (in excel) for detection of any genotyping error and null alleles. The evidence for significant deviation from population mutationdrift equilibrium (bottleneck) at 16 neutral MS markers in all populations was checked after Bonferroni correction, with 2,000 replicates under the two phase mutation model with 95\% step-wise mutations ( $\mathrm{Ps}=0.95$ ) using BOTTLENECK program [16]. Measures of genetic diversity such as total number of alleles, allele frequencies, mean number of alleles (MNA), polymorphism information content (PIC), observed and expected heterozygosity $(\mathrm{Ho}, \mathrm{He})$ and fixation index $(\mathrm{F})$ were computed using GenAlEx ver.6.5 [17]. Nei genetic distances were computed using the aforesaid software. Allele richness (AR) was calculated using FSTAT 2.9.3 [18]. Pairwise genetic differentiation (Wright's F statistics) and analysis of molecular variance (AMOVA) analysis were performed using Arlequin ver. 3.5 [19]. Neighbor-Joining phylogenetic tree was constructed based on Nei's standard genetic distance model with 1,000 bootstraps using the software POPTREE2
[20]. Genetic structure of the studied chicken populations was inferred by model-based clustering using STRUCTURE ver. 2.3.4 [21] with a burn period of 20,000 generations and Markov Chain Monte Carlo simulations of 100,000 iterations. The optimal $\mathrm{K}$ values were determined having the lowest cross-validation $(\mathrm{CV})$ errors $(\Delta \mathrm{K}=3.74)$. Discriminant analysis of principal component (DAPC) analysis in R, aims to provide an efficient description of genetic clusters using a few synthetic variables. These are constructed as linear combinations of the original variables (alleles) which have the largest between-group variance and the smallest withingroup variance [22].

\section{RESULTS AND DISCUSSION}

\section{Distribution and morphological features of the experimental birds}

Table 1 represents the morphological characteristics and distribution of the investigated chicken samples of Bangladesh. ND and NN are scattered throughout the country except in the hilly areas. Besides, HI chickens are predominantly available in Chittagong Hill tracts. The AS is mostly concentrated in Sarail Upazila of Brahmanbaria district as well as in the peri-urban and urban areas of Dhaka, Chittagong, and Sylhet division. All birds possess single comb type with few exceptions in AS chicken which have a strawberry comb. All the chicken varieties have whitish and/or yellowish shank color except red jungle fowl that possesses slate /blackish shank color. Bhuiyan et al [4], Faruque et al [23] and Sarker et al [24] previously reported the morphological features and geographic distribution of Bangladeshi indigenous chickens that support the present findings.

\section{Genetic diversity measures within and among the}

Table 1. Morphological features of Bangladeshi chicken populations and JF used in this study

\begin{tabular}{|c|c|c|c|c|c|}
\hline \multirow{2}{*}{$\begin{array}{l}\text { Type/ } \\
\text { variety }^{1)}\end{array}$} & \multirow{2}{*}{$\begin{array}{l}\text { No. of } \\
\text { sample }\end{array}$} & \multirow{2}{*}{ Distribution } & \multicolumn{3}{|c|}{ Morphological characteristics } \\
\hline & & & Comb type & Plumage & Shank \\
\hline ND & 41 & Throughout the country & Single & Reddish brown or reddish black & White, yellow, black \\
\hline $\mathrm{HI}$ & 39 & Chittagong hill tract region & Single & Black dotted on white and Grey or reddish & Whitish, yellow, black \\
\hline NN & 46 & Throughout the country & Single & Black and/or reddish black & White, yellow, black \\
\hline$J F$ & 17 & $\begin{array}{l}\text { Hilly areas of the Chittagong region and in } \\
\text { Sundarban (the largest mangrove forest) }\end{array}$ & Single & $\begin{array}{l}\text { Mixed feather colors with orange, } \\
\text { brown, red, gray, white, and even } \\
\text { metallic green plumage }\end{array}$ & Blackish/slate color \\
\hline
\end{tabular}




\section{populations}

In total, 171 alleles were detected from 16 polymorphic markers (Table 2). The 16 MS markers had an average of 10.7 alleles where the mean $\mathrm{Ho}, \mathrm{He}$, and polymorphism information content (PIC) were $0.669,0.71$ and 0.749 , respectively. The ADL0259 marker had the highest number of alleles (16) while ADL0268 possessed the lowest number of alleles (6). The PIC values of locus were ranged between 0.598 (ROSS013) and 0.843 (MCW104) among the studied loci (Table 2). No evidence was observed for possible bottleneck effect in any of the populations using 16 loci. At marker level diversity, the present results are in agreement with the findings of Seo et al [25] who reported that the $\mathrm{Ho}, \mathrm{He}$, and PIC ranged from 0.709 to $0.882,0.466$ to 0.852 , and 0.648 to 0.865 , respectively in Korean native chicken lines. On the other hand, considering five chicken populations of Bangladesh, the overall MNA was $7.06 \pm 0.45$ (Table 3). The lowest MNA was found in JF (5.81 \pm 0.46$)$ whereas the highest number of alleles was found in ND (7.13 \pm 0.52$)$. The highest Shanon's information index, an estimator of diversity index ranged between $1.40 \pm 0.08$ and $1.54 \pm 0.08$ in ND and AS, respectively. The average $\mathrm{Ho}$ was $0.67 \pm 0.01$ among the investigated populations. However, the highest $H o$ was found in $\mathrm{NN}(0.71 \pm 0.03)$ and the lowest heterozygosity $(0.64 \pm 0.03)$ possessed by ND and $\mathrm{HI}$ chicken populations. On the other hand, the average Neis unbiased $\mathrm{He}$ was $0.70 \pm 0.01$ for all loci and varied between $0.68 \pm 0.03$ and $0.70 \pm 0.03$ in ND and NN chicken populations, respectively (Table 3 ). The overall fixation index $(F)$ was found $0.04 \pm 0.02$ for all loci with a range between -0.02 $\pm 0.02(\mathrm{NN})$ and $0.08 \pm 0.03(\mathrm{JF})$. The findings of the current study on MNA, $\mathrm{Ho}$, and $\mathrm{He}$ are in concordance with Chinese, Ethiopian and Tanzanian chicken populations reported in several literatures[13,26-28]. However, the MNA observed in the present study were lower than those reported values of Pirany et al [9] and Dorji et al [7]. They found the average MNA were $10.33 \pm 4.33$ and $14.17 \pm 0.93$, respectively, in Indian and Bhutanese chicken populations. By contrast, Van Marle-Köster and Nel [11] reported relatively lower MNA

Table 2. Polymorphism information and F- statistics of microsatellite markers used in this study

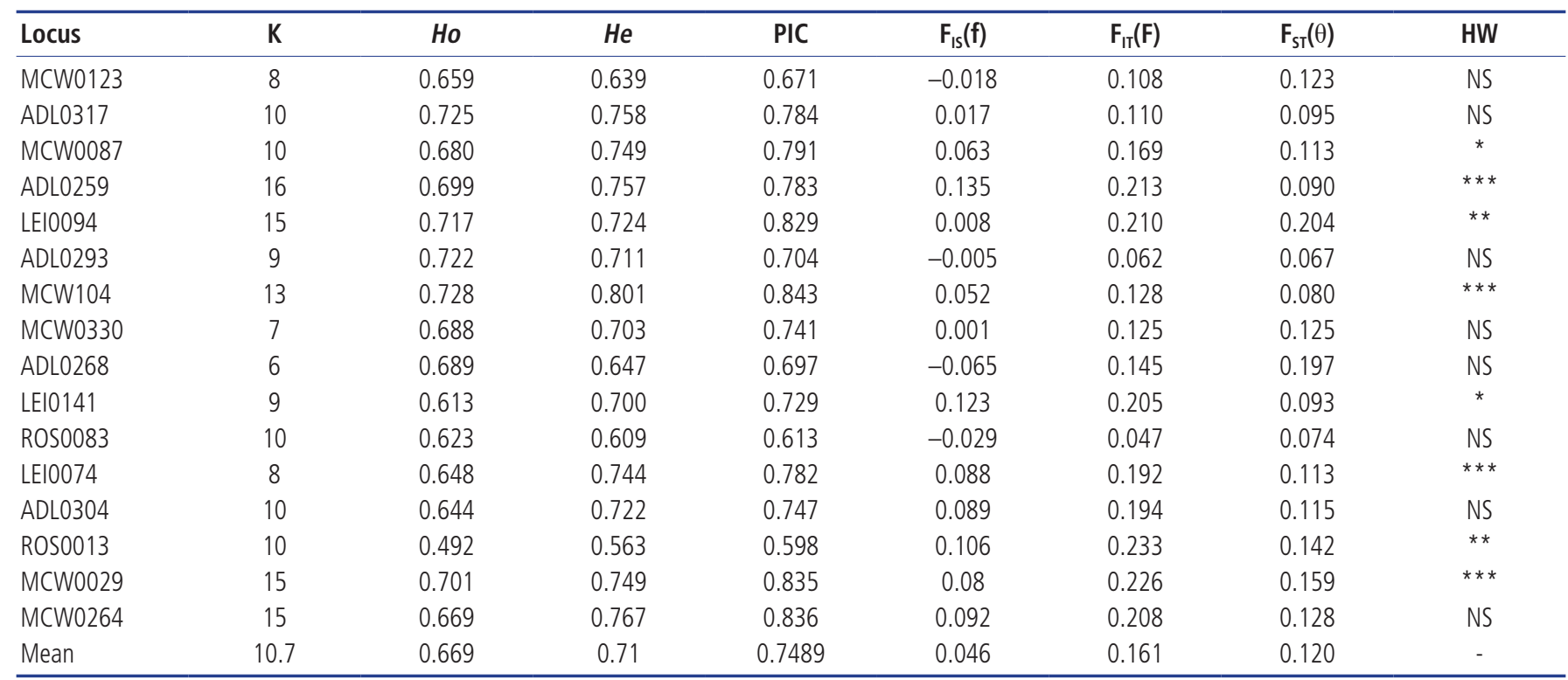

$\mathrm{K}$, number of alleles in all population; Ho, observed heterozygosity per locus; He, expected heterozygosity; PIC, polymorphic information content; Weir and Cockerham [31] estimation of $F_{I T}(F), F_{I S}(f)$ and $F_{S T}(\theta)$; HW, Hardy-Weinberg equilibrium test (with Bonferroni correction).

Table 3. Genetic diversity measures of 5 chicken populations using 16 polymorphic markers

\begin{tabular}{lcccccccc}
\hline Population $^{1)}$ & N & Na & Range & I & AR & Ho & He & F \\
\hline ND & 41 & $7.13 \pm 0.52$ & $5-11$ & $1.40 \pm 0.08$ & 5.76 & $0.64 \pm 0.03$ & $0.67 \pm 0.03$ & $0.04 \pm 0.03$ \\
NN & 46 & $6.81 \pm 0.51$ & $4-11$ & $1.43 \pm 0.06$ & 5.58 & $0.71 \pm 0.03$ & $0.70 \pm 0.02$ & $-0.02 \pm 0.02$ \\
HI & 39 & $6.56 \pm 0.47$ & $3-10$ & $1.44 \pm 0.08$ & 5.78 & $0.64 \pm 0.03$ & $0.69 \pm 0.02$ & $0.07 \pm 0.04$ \\
JF & 17 & $5.81 \pm 0.46$ & $3-10$ & $1.41 \pm 0.06$ & 5.73 & $0.65 \pm 0.03$ & $0.70 \pm 0.02$ & $0.08 \pm 0.03$ \\
AS & 18 & $7.06 \pm 0.45$ & $4-11$ & $1.54 \pm 0.08$ & 6.82 & $0.70 \pm 0.04$ & $0.72 \pm 0.03$ & $0.02 \pm 0.05$ \\
Overall mean & - & $7.06 \pm 0.45$ & - & $1.44 \pm 0.03$ & 5.93 & $0.67 \pm 0.01$ & $0.70 \pm 0.01$ & $0.04 \pm 0.02$ \\
\hline
\end{tabular}

N, No. of observation; Na, number of alleles; I, Shanon's information index; AR, allele richness; Ho, observed heterozygosity; He, expected heterozygosity; F, fixation index across loci for each population.

1) ND, non-descript Deshi; HI, hilly; NN, naked neck; JF, jungle fowl; AS, Aseel. 
than the current findings that ranged from 2.3 to 4.3 in five African chicken lines.

Comparing to the present results on $\mathrm{Ho}$ and $\mathrm{He}$, Rudresh et al [29] reported higher values ( 0.69 to 0.86 ) in two chicken populations of Karnataka, India while lower estimates ( 0.44 to 0.58 ) were found in Thai and Bhutanese native chickens [7]. It is notable to mention that direct comparison of data from different studies is probably difficult due to the different genetic backgrounds of the chicken populations studied and the different MS markers used [26]. The differences in MNA, $\mathrm{Ho}$, and $\mathrm{He}$ between previous and present findings may be attributed with sample size, population structure, number of markers used, population specific alleles and/or allele scoring bias (null allele or allele drop out) and sampling strategy. The higher MNA, and mean allele richness values estimated based on the minimum sample size 17 and weighted over 16 loci indicated relatively higher genetic diversity in all populations and therefore, Bangladeshi chicken populations are more diverse. Markers with PIC values $>0.5$ and $\mathrm{He}$ values $>0.6$ provided high PIC for genetic diversity measures and were most reliable for population discrimination $[25,30]$. The present study confirmed that all markers had higher PIC and $H e$ values than the truncated level, except for ADL0304. Taken together, the observed high heterozygosity value, PIC, Shanon's Information Index (Tables 2, 3) indicated that the selected $16 \mathrm{MS}$ markers were reliable and informative for estimating the genetic diversity in indigenous chicken population of Bangladesh.

According to Weir and Cockerham [31] estimation, the overall within population inbreeding $\left(\mathrm{F}_{\mathrm{IS}}\right)$ was found to be 0.046 considering all 16 loci and varied between -0.07 (LEI 0268 locus) and 0.14 (ADL0259 locus) (Table 3). The overall heterozygote deficiency or total inbreeding $\left(\mathrm{F}_{\mathrm{IT}}\right)$ and mean genetic distance $\left(\mathrm{F}_{\mathrm{ST}}\right)$ were 0.16 and 0.12 , respectively, over the 16 loci. Seo et al [25] discriminated five Korean native chicken lines using 15 highly polymorphic MS markers where the estimated mean $\mathrm{F}_{\mathrm{IS}}, \mathrm{F}_{\mathrm{IT}}$ and $\mathrm{F}_{\mathrm{ST}}$ values were $0.0093,0.137$, and 0.129 , respectively and is comparable to the present study. Furthermore, Chen et al [27] reported the mean $\mathrm{F}_{\mathrm{IS}}$ and $\mathrm{F}_{\mathrm{IT}}$ values to be 0.002 and 0.18 , respectively, in fifteen Chinese Indigenous chicken breeds and are comparable to the present study. The $\mathrm{F}_{\mathrm{IS}}$ represents a degree of non-random mating (deviation from Hardy-Weinberg equilibrium) where a positive value for $\mathrm{F}_{\mathrm{IS}}$ means selective breeding population. Only five (MCW0123, LEI0094, ADL0293, ADL0268, ROS0083) out of 16 markers showed a negative number. This result indicated the absence of random mating in the investigated chicken populations, which was supported by Faruque et al [8] who reported that three indigenous chicken varieties (ND, NN, and $\mathrm{HI}$ ) were under selective breeding for a decade at the institutional flocks. Consequently, the rate of inbreeding has been increased over the generations. In ad- dition, the higher $\mathrm{F}_{\mathrm{IT}}$ value of the present study was due to excessive homozygosity existing in six MS markers (MCW 0029, MCW0264, ROS0013, ADL0304, LEI0074, and LEI 0141).

\section{Genetic distances and clustering of the indigenous chicken varieties}

Genetic distances: The populations pairwise distances $\left(\mathrm{F}_{\mathrm{ST}}\right)$ among the studied populations were found significant $(\mathrm{p}<$ 0.01 ) and the values ranged between 0.084 and 0.154 (Table 4). The highest pairwise genetic distance (0.154) was found between ND and AS while the lowest distance was observed between JF and AS (0.084). Nei's unbiased genetic distance results were also in agreement with pairwise genetic distances showing highest distance (0.578) between ND and AS, whereas the lowest genetic distance (0.285) was between AS and JF. The AMOVA results showed the genetic variation among the 5 populations was $11.93 \%$ while the remaining $88.07 \%$ of the total variation was accounted for within population diversity with an overall $\mathrm{F}_{\mathrm{ST}}$ value of $0.12(\mathrm{p}<0.001)$ (Figure 1). Several previous studies reported higher $F_{S T}$ values $(0.15$

Table 4. Population pairwise $F_{S T}$ (above diagonal) and Nei's unbiased genetic distance (below diagonal) for five chicken populations of Bangladesh

\begin{tabular}{lccccc}
\hline Items & ND & NN & HI & JF & AS \\
\hline ND & - & $0.125^{* *}$ & $0.112^{* *}$ & $0.139^{* *}$ & $0.154^{* *}$ \\
$\mathrm{NN}$ & 0.391 & - & $0.118^{* *}$ & $0.123^{* *}$ & $0.138^{* *}$ \\
$\mathrm{HI}$ & 0.337 & 0.390 & - & $0.091^{* *}$ & $0.092^{* *}$ \\
$\mathrm{JF}$ & 0.475 & 0.429 & 0.292 & - & $0.082^{* *}$ \\
$\mathrm{AS}$ & 0.578 & 0.529 & 0.305 & 0.285 & - \\
\hline
\end{tabular}

ND, non-descript Deshi; NN, naked neck; HI, hilly chicken; JF, jungle fowl; AS, Aseel. ** $p<0.05$.

\section{Percentages of Molecular Variance}

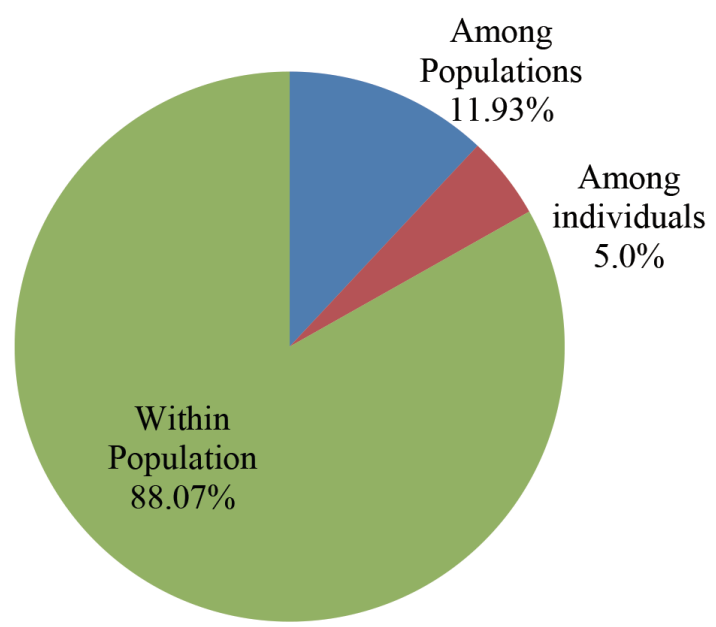

Figure 1. Analysis of molecular variance calculated based on the allelic distance matrix of $\mathrm{F}_{\mathrm{ST}}$ statistics among five chicken populations of Bangladesh. F-statistics were significant at $p<0.05$. 
to 0.26) in Indian [14], Chinese [27] and African indigenous chicken populations [10] and depicted that comparatively lower genetic distances existed among the Bangladeshi chicken varieties. On the contrary, Halima et al [26] reported the genetic distances in seven North-west Ethiopian native chicken populations varied from 0.073 to 0.13 . Seo et al [25] found pairwise genetic distance among five Korean native chicken lines to be 0.083 to 0.171 . The above two findings are similar to the present study. In addition, the current results are supported by the study of Yamamoto et al [32] who reported the lower genetic differentiation among the different Bangladeshi chicken populations. Bhuiyan et al [5] found low $\mathrm{F}_{\mathrm{ST}}$ value (0.1084) for Bangladeshi chicken varieties using mtDNA D-loop sequence analysis and strongly justified the results of this study as evidenced by population pairwise $\mathrm{F}_{\mathrm{ST}}$ and AMOVA analysis. Altogether, the low genetic differentiation among the Bangladeshi chicken populations might be due to recent gene flow among themselves as well as common ancestor for constructing the populations.

Phylogenetic analysis: The Nei's unbiased genetic distance matrices and dendrogram have shown that $\mathrm{NN}$ and ND were grouped into the same branch (Table 4, Figure 2). The three other chicken varieties AS, HI, and JF made a separate cluster which revealed the close relatedness among themselves. Notably, HI was separated from AS and JF with a node that signifies $\mathrm{HI}$ as a distinct chicken variety. Bhuiyan et al [4] and Faruque et al [8] reported ND, NN, and HI were distinct indigenous chicken varieties of Bangladesh where $\mathrm{HI}$ are geographically isolated from others and supports the present findings. This phenomenon could also be explained from the geographic history, as both JF and HI are the inhabitants of Chittagong Hill Tract regions and might be separated from the common origin in the recent past. AS is an established fighting breed but has a close relationship with JF. This might be due to the fact of inter se mating between AS and JF, a long tradition to the farmers, for increasing vigor and aggressiveness in AS birds (personal communication). The phylogenetic tree also suggested the possible introgression of JF to AS breed and compatible with the previous mitochondrial DNA study [5]. Besides, ND and NN are evenly distributed throughout the country. Gene flow between these two populations is not unlikely and therefore, they belong to the same cluster due to their close genetic relationships.

Structure program was employed to investigate the genetic structure of the 5 chicken populations of Bangladesh (Figure 3 ). The results showed better agreement in structure output at $\mathrm{K}$ values between 4 and 5 . The output at $\mathrm{K}=5$ seems plausible; it clearly distinguished each chicken population. This result is supported by the findings of Cho et al [15] and Seo et al [25] where they reported Korean native chicken breeds (five or six) had an equal number of underlying genetic clus-

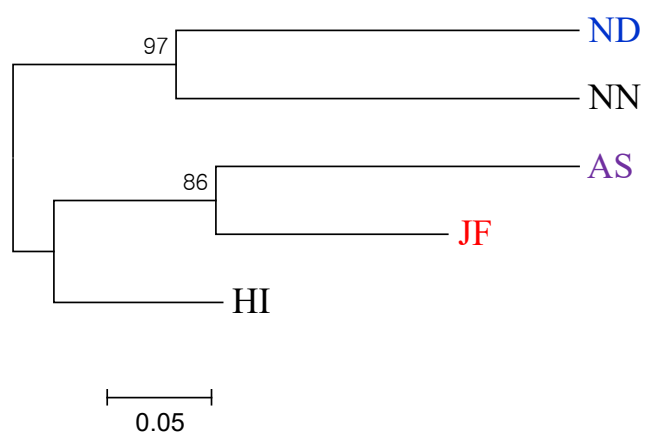

Figure 2. Neighbor-Joining phylogenetic tree based on standard genetic distance (Nei, 1972) depicting relationships among five indigenous chicken populations of Bangladesh. ND, non-descript Deshi; NN, naked neck; HI, hilly; JF, red jungle fowl; AS, Aseel.

ters $(\mathrm{K}=5$ or 6$)$. The $\Delta \mathrm{K}$ statistic was 3.74 at a maximum $K$ value $(K=5)$, which suggest the most probable number of inferred clusters. Structure data also indicated a certain portion of genetic admixture in each population from other varieties. Moreover, structure analysis also depicted remarkable introgression of JF into AS, which was supported by the findings of Bhuiyan et al [5] and Sarker et al [24]. K-means based genetic clustering in DAPC analysis was given at Kmean = five (lowest BIC value) and group membership values (data not shown) were consistent with structure results. Efficient description of genetic clusters among Bangladesh chicken illustrated in DAPC plot (Figure 4) also provides membership probabilities of individuals for the different groups based on the retained discriminant functions. DAPC result was similar to structure results indicating that all groups were discriminated, however, a close proximity between AS, JF, and HI was observed. It is noteworthy to mention that the genetic basis of the founder population of these five chicken varieties was not well defined as well as a bit complicated. Eggs were screened from the farmers merely based on phenotypic information from the random mated population. They were being reared in scavenging condition and therefore, some gene flow in neighbouring regions or populations possibly exists. Taken together, this study provides important information on genetic background of indigenous chicken genetic resources of Bangladesh that could be utilized for conservation and subsequent improvement.

\section{IMPLICATIONS}

The molecular study showed that indigenous chicken of Bangladesh still possesses rich genetic diversity. Analysis of molecular variance analysis revealed only $11.93 \%$ of the total genetic diversity accounted for between population differentiations $\left(\mathrm{F}_{\mathrm{ST}}\right)$ that indicates poor genetic variability among the investigated populations. The phylogenetic tree and discriminant 


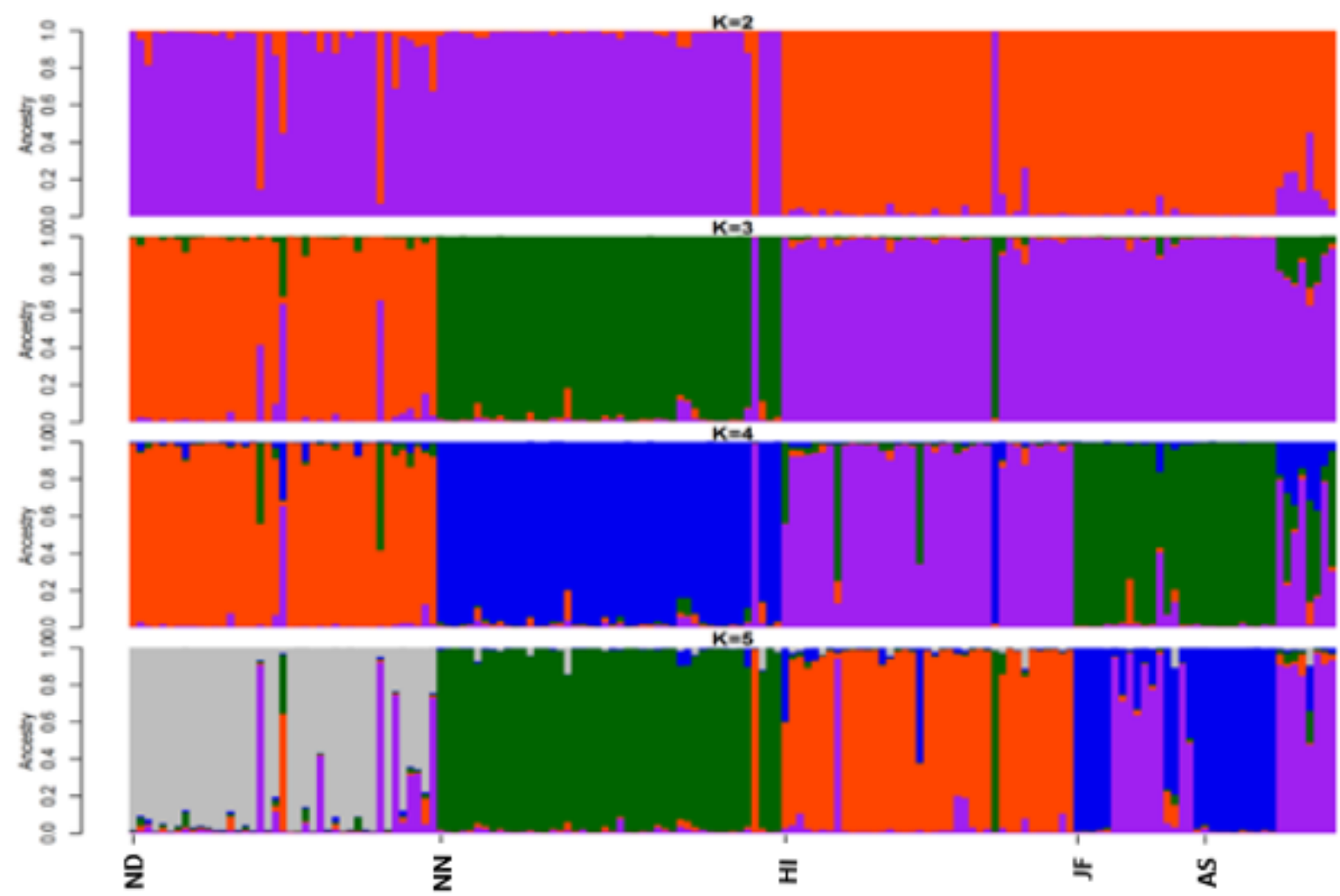

Figure 3. Structure clustering of indigenous chicken varieties among 5 different chicken populations of Bangladesh. The proportions of ancestral populations for each individual varying from $\mathrm{K}=2$ to 5 for population structure construction. ND, non-descript Deshi; NN, naked neck; HI, hilly; JF, red jungle fowl and AS, Aseel.

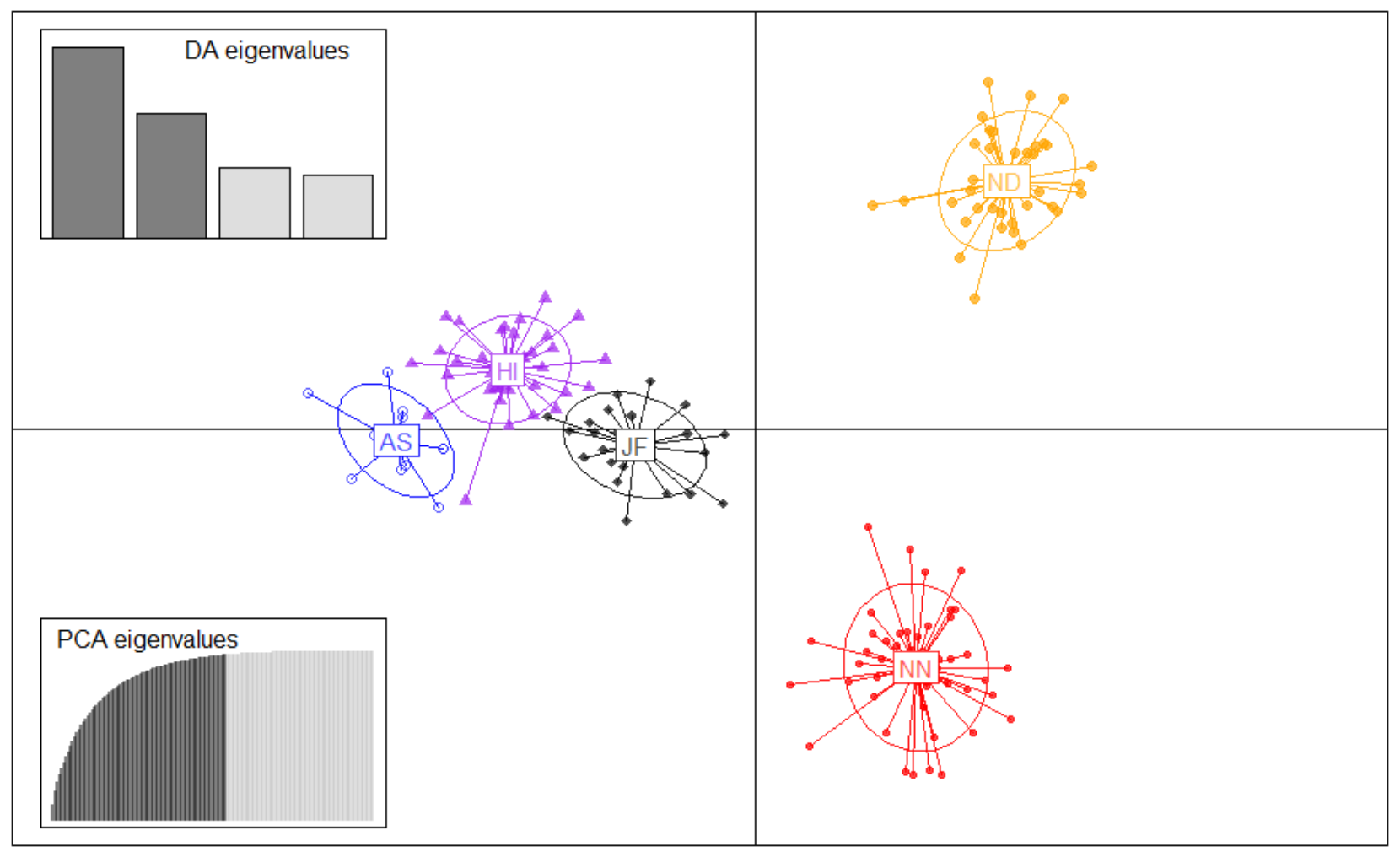

Figure 4. Discriminate analysis of principal component (DAPC) results using five different indigenous chicken population of Bangladesh. DAPC aims to provide an efficient description of genetic clusters using a few synthetic variables constructed as linear combinations of the original variables (alleles). 
analysis of principal component analysis showed hilly chicken appeared to be genetically closer to Aseel and red jungle fowl. Structure analysis depicted a certain amount genetic admixture among the five studied populations where massive introgression was found from red jungle fowl to Aseel. Altogether, this study provides some important insight information for the first time on genetic diversity measures and population structure inferences of Bangladeshi chicken populations using microsatellite markers.

\section{CONFLICT OF INTEREST}

We certify that there is no conflict of interest with any financial organization regarding the material discussed in the manuscript.

\section{ACKNOWLEDGMENTS}

The authors would like to thank the Native Chicken Conservation and Improvement Project (No. MOFL-4405-5017), BLRI, Bangladesh for funding this research. In addition, this work was supported by research fund from Chungnam National University, South Korea, especially for providing research facilities and associated costs of microsatellite genotyping.

\section{REFERENCES}

1. Ferdaus AJM, Bhuiyan MSA, Hassin BM, Bhuiyan AKFH, Howlider MAR. Phenotypic characterization and productive potentialities of indigenous dwarf chicken of Bangladesh. Bang J Anim Sci 2016;45:52-61. https://doi.org/10.3329/bjas. v45i1.27489

2. Das SC, Chowdhury SD, Khatun MA, Nishibori M, Isobe N, Yoshimura Y. Poultry production profile and expected future projection in Bangladesh. World's Poult Sci 2008;64:99-118. https://doi.org/10.1017/S0043933907001754

3. Bhuiyan AKFH. Implementation of National Livestock development Policy (2007) and National Poultry development Policy (2008): Impact on smallholder livestock rearers. Keynote paper presented at the South Asia Pro Poor Livestock Policy programme (SAPPLP)-BRAC workshop held at BRAC Centre Inn., 2011; Dhaka, Bangladesh.

4. Bhuiyan AKFH, Bhuiyan MSA, Deb GK. Indigenous chicken genetic resources of Bangladesh: Current status and future outlook. Anim Genet Resour Infor 2005;36:73-84. https:// doi.org/10.1017/S1014233900001899

5. Bhuiyan MSA, Chen S, Faruque S, Bhuiyan AKFH, BejaPereira A. Genetic diversity and maternal origin of Bangladeshi chicken. Mol Biol Rep 2013;40:4123-8. https://doi.org/10. 1007/s11033-013-2522-6

6. Islam MA, Seeland G, Bulbul SM, Howlider MAR. Meat yield and cooked meat taste of hybrids from different genetic groups in a hot-humid climate. Indian J Anim Res 2002;36:35-8.

7. Dorji N, Duangjinda M, Phasuk Y. Genetic characterization of Bhutanese native chickens based on an analysis of Red Jungle fowl (Gallus gallus gallus and Gallus gallus spadecieus), domestic Southeast Asian and commercial chicken lines (Gallus gallus domesticus). Genet Mol Biol 2012;35:603-9. https://doi.org/10.1590/S1415-47572012005000039

8. Faruque S, Islam MN, Bhuiyan AKFH. Ex situ improvement of indigenous chicken in Bangladesh. Trop Agric Res 2015; 26:596-607. http://doi.org/10.4038/tar.v26i4.8122

9. Pirany N, Romanov NMN, Ganpule SP, Govindaiah D, Doddananjat $\mathrm{P}$. Microsatellites analysis of genetic biodiversity in Indian chicken populations. J Poult Sci 2007;44:19-28. https:// doi.org/10.2141/jpsa.44.19

10. Mwacharo JM, BjØrnstad G, Mobegi V, et al. Mitochondrial DNA reveals multiple introductions of domestic chicken in East Africa. Mol Phylogenet Evol 2011;58:374-82. https:// doi.org/10.1016/j.ympev.2010.11.027

11. Van Marle-Köster E, Nel LH. Genetic characterization of native southern African chicken populations: evaluation and selection of polymorphic microsatellite markers. S Afr J Anim Sci 2000;30:1-6. http://dx.doi.org/10.4314/sajas.v30i1.3866

12. Weigend S, Romanov MN. Current strategies for the assessment and evaluation of genetic diversity in chicken resources. World's Poult Sci J 2001;57:275-88. https://doi.org/10.1079/ WPS20010020

13.Zhang X, Leung FC, Chan DK, Wu C. Genetic diversity of Chinese native chicken breeds based on protein polymorphism, randomly amplified polymorphic DNA, and Microsatellite polymorphism. Poult Sci 2002;81:1463-72. https:// doi:10.1093/ps/81.10.1463

14. Kanginakudra S, Metta M, Jakati RD, Nagaraju J. Genetic evidence from Indian red jungle fowl corroborates multiple domestication of modern day chicken. BMC Evol Biol 2008; 8:174. https://doi.org/10.1186/1471-2148-8-174

15. Cho N, Hoque R, Seo DW, et al. ISAG-recommended microsatellite marker analysis among five Korean native chicken lines. J Anim Sci Technol 2012;54:401-9.

16. Counute JM, Luikart G. Description and power analysis of two tests for detecting recent population bottlenecks from allele frequency data. Genetics 1996;144:2001-14.

17. Peakall R, Smouse PE. GenAlEX 6.5: Genetic analysis in Excel. Population genetic software for teaching and research an update. Bioinformatics 2012;28:2537-9. https://doi.org/10. 1093/bioinformatics/bts460

18. Goudet J. FSTAT ver.1.2: A computer program to calculate F-statistics. J Hered 1995;86:485-6. https://doi.org/10.1093/ oxfordjournals.jhered.a111627

19. Excoffier L, Lischer HEL. Arlequin suite ver. 3.5: A new series of programs to perform population genetics analyses under Linux and Windows. Mol Ecol Resour 2010;10:564-7. https:// 
doi.org/10.1111/j.1755-0998.2010.02847.x

20. Takezaki N, Nei M, Tamura K. POPTREE2: Software for constructing population trees from allele frequency data and computing other population statistics with windows interface. Mol Biol Evol 2010;27:747-52. https://doi.org/10.1093/molbev/ msp312

21.Pritchard JK, Stephens M, Donnelly P. Inference of population structure using multilocus genotype data. Genetics 2000; 155:945-59.

22. Jombart T, Collins C. A tutorial for discriminant analysis of principal components (DAPC) using adegenet 2.0.0. MRC center for Outbreak analysis and modeling; 2015 Jun 23; Imperial College London; South Kensington, London, UK. pp 9-42.

23. Faruque S, Siddiquee NU, Afroz MA, Islam MS. Phenotypic characterization of Native Chicken reared under intensive management system. J Bangladesh Agric Univ 2010;8:7982.

24. Sarker MJA, Bhuiyan MSA, Faruque MO, Ali MA, Lee JH. Phenotypic characterization of Aseel chicken of Bangladesh. Korean J Poult Sci 2012;39:9-15. http://dx.doi.org/10.5536/ KJPS.2012.39.1.009

25. Seo DW, Hoque MR, Choi NR, et al. Discrimination of Korean native chicken lines using fifteen selected Microsatellite markers. Asian-Australas J Anim Sci 2013;26:316-22. https://doi. org/10.5713/ajas.2012.12469

26. Halima HM, Neser FWC, De-Kock A, Van MKE. Study on the genetic diversity of native chickens in northwest Ethiopia using microsatellite markers. Afr J Biotechnol 2009;8:1347-53.

27. Chen G, Bao W, Shu J, et al. Assessment of population structure and genetic diversity of 15 Chinese indigenous chicken breeds using microsatellite markers. Asian-Australas J Anim Sci 2008;21:331-9. https://doi.org/10.5713/ajas.2008.70125

28.Lyimo CM, Weigend A, Janben-Tapken U, Msoffe PL, Samianer $\mathrm{H}$, Weigend $\mathrm{S}$. Assessing the genetic diversity of five Tanzanian chicken ecotypes using molecular tools. S Afr J Anim Sci 2013;43:499-510. http://dx.doi.org/10.4314/sajas. v43i4.7

29. Rudresh BH, Murthy HNN, Jayashankar MR, Nagaraj CS, Kotresh AM, Byregowda SM. Microsatellite based genetic diversity study in indigenous chicken ecotypes of Karnataka. Vet World 2015;8:970-6. http://dx.doi.org/10.14202/vetworld. 2015.970-976

30. Botstein DRL, White MS, Davis RW. Construction of a genetic linkage map in man using restriction fragment length polymorphisms. Am J Hum Genet 1980;32:314-31

31. Weir BS, Cockerham CC. Estimating F-statistics for the analysis of population structure. Evolution 1984;38:1358-70.

32. Yamamoto Y, Oka T, Faruque MO, Amano T. Genetic diversity and genetic relationship of Bangladeshi native chickens. In: Proceedings of the $7 \mathrm{~h}$ International Poultry Show and Seminar. World's Poultry Science Association, Bangladesh Branch; 2011. pp. 207-15. 